\title{
The Research of Islanding Detection about the Photovoltaic Grid-Connected Generation System
}

\author{
Zongjie Liu, Lifeng Zhu, Li Deng, Lijun Qin, and Feng Jiao
}

\begin{abstract}
The photovoltaic grid-connected generation system is rapidly developed and applied due to the cleaning, renewable and wide distribution of solar. This paper is to solve the problem about islanding detection brought by the photovoltaic grid-connected generation system. First of all, it analyses the reason happened and potential hazards of the Islanding and introduces the existing detection method and islanding detection. Then, in view of the insufficiency of the existing method, it put forward a new solution that combined the negative sequence voltage positive feedback voltage with active power positive feedback to the islanding detection. The amount of change of the frequency and the voltage is introduced to the voltage - active power positive feedback, which can effectively and fast detect the island.
\end{abstract}

Index Terms-Islanding detection, negative sequence positive feedback, photo voltaic grid-connected, voltage-active power positive feedback

\section{INTRODUCTION}

With the global warming and other environmental problems and fossil fuel exhausted and other energy worsening, the research of the use of renewable energy has become the focus of the study of the human beings in the 21 st century. In our country, the solar energy is widely distributed, which is expected to ease the power shortage situation. But a large number of photovoltaic power generation devices are injured to the grid, which will bring a new problem -islanding detection.

The island effect is that the photovoltaic grid-connected generation system of user side will be cut itself off from the power grid because fails to detect the change of state power when the power supply is suddenly stopped because of accident or maintenance, which will form a power supply area with surrounding load without control[1].

In fact, there is the same problem in the all of the distributed power supply. The island effect can cause major hazards are (1) to endanger the safe of maintenance personnel of the power company. (2) The capacity of photovoltaic island power supply system is less than the load capacity, which photovoltaic island power supply system may be easily burn by the overload condition. (3) Resulting in instability of the voltage and frequency in the photovoltaic island area. (4) after reclosing action, switch is cut off again, which may cause impact to the photovoltaic

Manuscript received October 22; 2012; revised November 24, 2012. This work was supported in part by the International Conference on Power Science and Engineering.

Zongjie Liu and Lifeng Zhu are with the Shandong Electric Power Group Corporation, J ining, China. (e-mail: jngdfz@163.com).

Li Deng, Lijun Qin, and Feng Jiao are with North China Electric Power University, Beijing, China. (e-mail: jiao3395@ sohu.com). grid-connected generation system and other electrical equipment. Visibility, it is very significant to research the islanding detection and relevant protection measures to eliminate the impact caused by island effect.

\section{EXISTING ISLANDING DETECTION METHOD}

It has small capacity and high cost in the distributed generation system. So it does not to communicate with the power grid control system, the islanding detection is achieved by the self-test of the inverter.

The islanding detection is achieved through monitoring the terminal voltage and current signals of power generation device to detect the islanding effect in the power supply side of distributed generation system, divided into active detection and passive detection two [2].

\section{A. Passive Detection}

\section{1) Over/under voltage and ver/under frequency method}

When islanding effect happened, the imbalance of active power will cause the change of frequency and the imbalance of reactive power will cause the change of voltage. If the change of frequency and voltage exceeds the threshold value, the over/under voltage and over/under frequency detection device will send alarm and stop the output of inverter or switch to island operation mode. As shown in Fig. 1, the load is expressed as RLC equivalent circuit, the impedance of the load for

$$
\begin{gathered}
Z=|Z| \angle \varphi \\
|Z|=\frac{1}{\sqrt{\frac{1}{R^{2}}+\left(\frac{1}{w l}-w C\right)^{2}}} \\
\varphi=\operatorname{actan}\left[R\left(\frac{1}{w L}-w C\right)\right]
\end{gathered}
$$

When breaker is closed, PV system is parallel running to provide $\mathrm{P}+\mathrm{jQ}$ power to a point, and the load get active power $\mathrm{P}_{\text {load }}$ and reactive power $\mathrm{Q}_{\text {load }}$, the power is provided by power grid for:

$$
\begin{aligned}
& \Delta P=P_{\text {load }}-P \\
& \Delta Q=Q_{\text {load }}-Q
\end{aligned}
$$

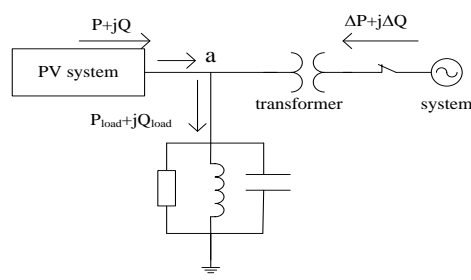

Fig. 1. Block diagram of grid-connected PV system 
It has defect is that the detection method will be failure when the capacity of distributed power supply is match with the capacity of load.

\section{2) Phase mutation detection method}

When distributed power supply is connected to the power grid, power factor for 1 , the output current, frequency and phase is completely consistent, and the phase difference is zero between the output voltage and current. When the powers supply loss, the load will be supplied by photovoltaic grid-connected generation system. At the same time, the phase of the voltage and current depends on the load.

For RLC load, when power supply loss, the phase of output voltages

$$
\varphi=\tan ^{-1}\left[R\left(2 \pi f C-\frac{1}{2 \pi f L}\right)\right]
$$

Phase mutation detection method is simple and can be realized easily. But when the load impedance angle is close to zero, it will be failure due to the limitation of the set threshold value.

\section{3) Harmonic detect}

When distributed power supply is connected to the power grid, because the resistance is small in the big power grid, shown in Fig. 1, the total harmonic distortion rate is very low at a point. When the island formed, the output current of inverter will flow into the load, because the load impedance is more than the internal resistance of the big power grid, which will produce great harmonic voltage. It can detect the harmonic voltage to in judge island form or not at the point of common coupling [3].

It has also defect is that the action threshold value is difficult to determine. It will be failure when the islanding system does not has a distribution transformer or a strong low-connectedness loads or non-linear loads require matching the harmonic current needs injection with the harmonic current output by inverter.

\section{B. Active Detection}

\section{1) Active frequency drift ( $A F D$ )}

AFD is implemented by adding a short period of zero time in the output current of the inverter based DG. As shown in Fig. 2, the DG output current reaches the zero point when voltage doesn't. The current will remain zero to wait. This detection scheme can be used in a system with more than one inverter based DG.

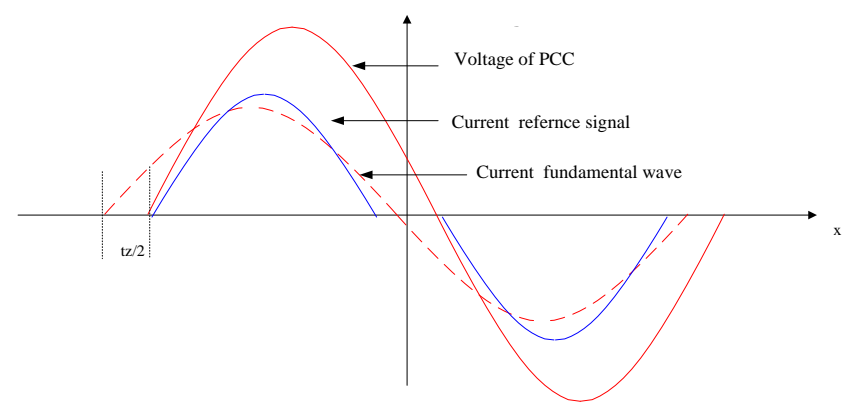

Fig. 2. Schematic diagram of AFD

Because phase of impedance load $\varphi=0$ introduces positive frequency offset $\Delta \mathrm{f}$, under the action of phase lock loop, the frequency of the inverter terminal voltage increased to $\mathrm{f}_{0} \pm \mathrm{k} \Delta \mathrm{f}$ the kth period after system is islanded. When frequency exceeds the threshold value, the island can be detected. The problem with the AFDPF is that the phase angle of a parallel RLC load depends on the operating frequency and this sometimes may result in islanding not being detected.

\section{2) Reactive power export error detection}

As for the inverter which can export both active and reactive power, to detect the reactive power demand of load at all times. The DG generates a level of reactive power flow to break the balance of reactive power. This power flow can only be maintained when the grid is connected Islanding can be detected if the level of reactive power flow is not maintained at the set value. The drawbacks of this method are the control measurement is complex and the existence of nonlinear load will cause large voltage harmonic of grid which will makes the action threshold hard to determine [4].

With active methods, islanding can be detected even under the match of generation and load, which is not possible in case of the passive detection methods. Active methods directly interact with the power system operation by introducing perturbations. However, these methods are not suitable for in the system where DG has to generate power at unity power factor because of the asynchronous disturbance.

\section{THE COMBINED IsLANDing Detection Method of Negative Sequence Voltage Positive FeEdBacKand IMPROVED VolTAGE-ACTIVE POWER POSITIVE FEEDBACK}

This paper proposes a new islanding detection principle to overcome the shortages of existing methods. The combined method can extract negative sequence voltage to make positive feedback the moment island is formed to improve the flexibility. Under the perfect match of load and generation, improved voltage-active power positive feedback is applied to enhance the reliability.

\section{A. Introduction of Negative Sequence Voltage Positive Feedback Based on D-Q Transform}

The terminal where DG is connected to the distribution system will generate negative sequence voltage when island formed [5]. The value is determined by the matching degree of Photovoltaic power and load. Negative sequence voltage positive feedback refers to introduce the feedback of negative sequence voltage to $\mathrm{d}-\mathrm{q}$ axis circuit. Thus the negative sequence current component exists in the reference current of d-q axis and under the effect of positive feedback, negative sequence voltage will increase continuously until island is detected.

As shown in Fig. 3, when voltage of PCC is introduced to $\mathrm{d}-\mathrm{q}$ control loop, reference current of grid-connected inverter can be given by:

$$
\left[\begin{array}{l}
i_{d} \\
i_{q}
\end{array}\right]=\left[\begin{array}{l}
i_{d}^{\prime \prime}+V_{a} \sin (w t) \\
i_{q}^{\prime \prime}+V_{a} \cos (w t)
\end{array}\right]
$$

After park transformation, inverter reference current 
under abc coordinate system can by described as:

$$
\left[\begin{array}{l}
i_{a} \\
i_{b} \\
i_{c}
\end{array}\right]=\left[\begin{array}{c}
i_{m} \sin (w t)+V_{a} \sin (w t) \\
i_{m} \sin \left(w t-120^{\circ}\right)+V_{a} \sin \left(w t+120^{\circ}\right) \\
i_{m} \sin \left(w t+120^{\circ}\right)+V_{a} \sin \left(w t-120^{\circ}\right)
\end{array}\right]
$$

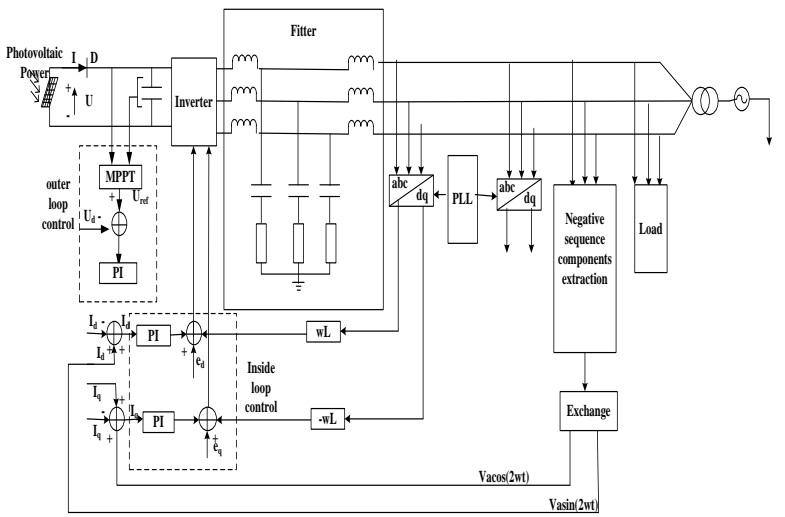

Fig. 3. Schematic diagram of negative sequence voltage positive feedback

Then, in island condition, positive sequence current generate positive sequence load voltage and negative sequence current generates negative sequence load voltage. Detect the ratio of negative sequence voltage effective value and positive sequence voltage effective value. According to $\mathrm{GB} / \mathrm{T} 15543-2008$, the normal voltage imbalance is no more than $2 \%$, short-term imbalance is no more than $4 \%$. Therefore, the criterion of negative sequence voltage positive feedback method is given by:

$$
\left\{\begin{array}{cc}
0 \leq V_{n}<\varepsilon_{1} V_{p} & \text { feedback in normal operation } \\
V_{n} \geq \varepsilon_{1} V_{p} & \text { send out alarm signal } \\
V_{n} \geq \varepsilon_{2} V_{p} & \text { detemine island formation }
\end{array}\right.
$$

where: $\varepsilon_{1}$ is $0.75 \% ; \varepsilon_{2}$ is $4 \% ; V_{n}$ refers to negative sequence voltage effective value; $V_{p}$ refers to positive sequence voltage effective value.

\section{B. Introduction of Improved Voltage-Active Power Positive Feedback Method}

The voltage and frequency of PCC will change greatly after photovoltaic grid-connected system becomes island. The relationship can be described as follows:

$$
\begin{gathered}
P_{L}=V^{2} /_{R} \\
Q_{L}=V^{2}\left[(w L)^{-1}-w C\right]
\end{gathered}
$$

When PCC voltage is detected increased, analyze according to formula (10): active demand of load is increase. The positive output of photovoltaic power generator is enhanced through the active power feedback. Then, active power of load is increased relevantly which result in the continuous enhance of PCC voltage. Island is detected when start component detect the voltage is out of limit.

This paper put forward a developed voltage-active power positive feedback algorithm based on $\mathrm{d}-\mathrm{q}$ transformation which combines voltage-active power positive feedback theory and $\mathrm{d}-\mathrm{q}$ transformation theory together. In addition, frequency variation is introduced to enhance the adaptive ability of voltage-active power positive feedback. When converter is connected to the grid, positive feedback doesn't take part in active power regulation. While, in island condition, with the continuous variation of frequency and voltage because of active feedback, the rate of detecting island is increased when regulation factor $\mathrm{N}$ makes feedback enhanced as time goes by.

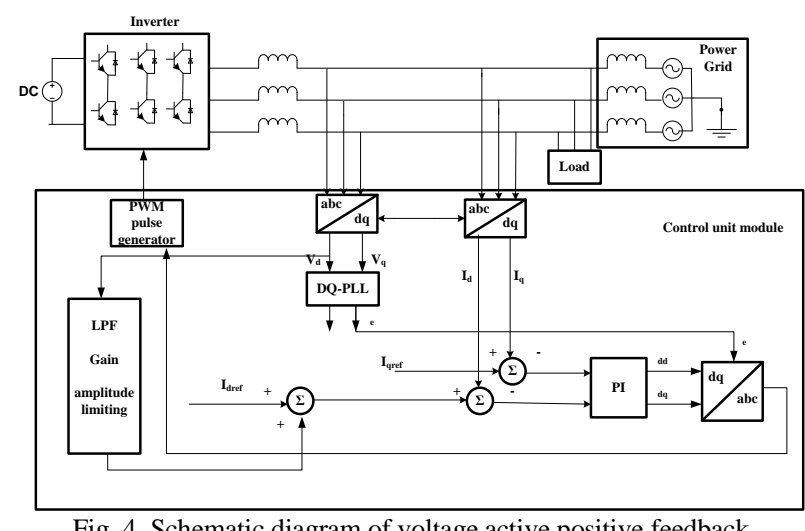

Fig. 4. Schematic diagram of voltage active positive feedback

To make distributed generation transfer power in integer power factor to grid when connected to the utility, set reference current of reactive power $\mathrm{q}$ axis a constant to balance reactive power of local load. Hence, when island is formed, reactive power the distributed generation sends has no change, the variation of active power will introduce the variation of voltage and the frequency. When reactive power is constant, there is positive correlation between frequency variation and voltage variation. So, introduction of frequency variation will accelerate mismatching degree of load and generation.

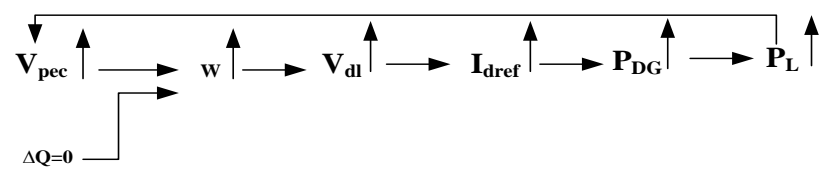

Fig. 5. Diagram of frequency active feedback

Conclude from the above analyses, detection becomes more flexible if combines frequency variation in the voltage-active power feedback.

$V_{d l}=$

$\left\{\begin{array}{c}\text { periodic disturbance }\left|V_{d}-V_{d \circ g}\right|<V_{\delta} \text { and }\left|f-f_{g}\right|<f_{\delta} \\ \left|k_{1} N_{1}\right|\left(\frac{f-f_{g}}{f_{g}}\right) V_{d \circ g}\left|+k_{2} N_{2}\right| V_{d}-V_{d \circ g}|| \operatorname{sign}(\Delta f) \\ \left|V_{d}-V_{d \circ g}\right| \geq V_{\delta} \text { and }\left|f-f_{g}\right| \geq f_{\delta}\end{array}\right.$

where: $V_{d l}$ is feedback voltage, $V_{d}$ is $d$ axis component of PCC, $V_{d} \circ g$ is d axis component of grid, $f$ is frequency of PCC, $f_{g}$ is frequency of grid $(50 \mathrm{~Hz}), f_{\delta}$ is frequency threshold value, $\Delta f$ is deviation of present frequency and grid frequency, $k_{1} \cdot k_{2}$ are positive and negative feedback gain, $N_{1} \cdot N_{2}$ are automatic regulation time.

C. Introduction of Combined Islanding Detection Method of Negative Sequence Voltage Positive Feedback and Improved Voltage-Active Power Positive Feedback

Through this combined method, voltage-active power 
positive feedback method can detect whether the system is under perfect match of load and generation. If not match, negative sequence voltage positive feedback method can operate immediately to detect island [6].

In normal operation, both methods work. For there is no negative sequence in stable condition, negative sequence voltage is working to monitor system operation. When island formed, negative sequence voltage positive feedback detect the negative sequence component exceeds the threshold value in short time, start to lockout voltage-active power positive feedback and successfully detect island mode. In match of load and generation, negative sequence voltage cannot exceed threshold value in short time. So, after two periods, lockout negative sequence voltage positive feedback and send out a disturbance to control circuit to put voltage-active power positive feedback to feedback mode. The following block diagram describes the realization of algorithm, as shown in Fig. 6.

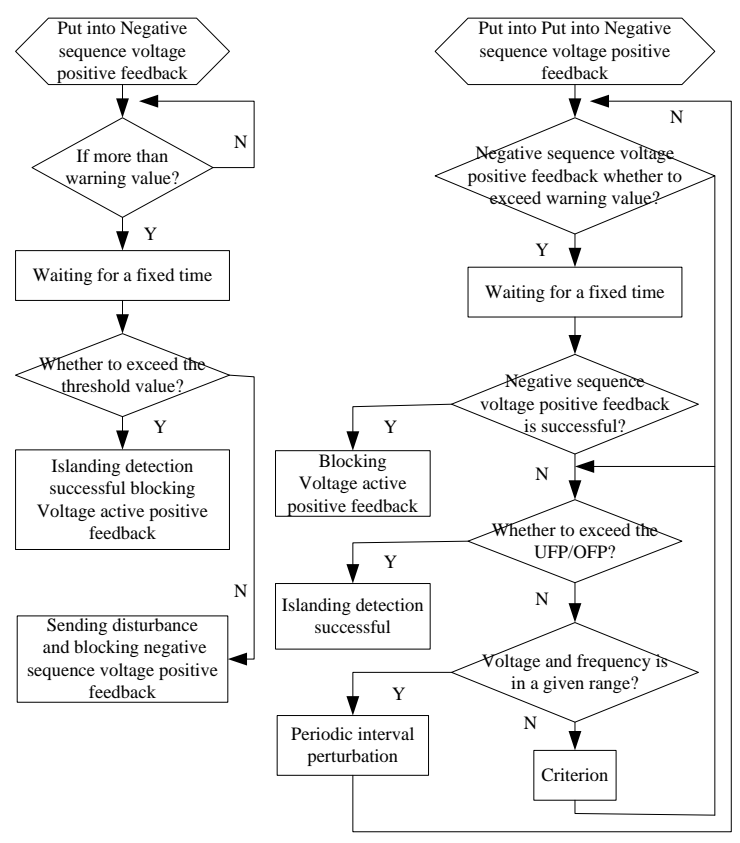

Fig. 6. The block diagram of the algorithm

\section{CONCLUSION}

By analyzing the existing islanding detection scheme, introduce a new method. In this method, the introduction of frequency variation to voltage-active power positive feedback improves effectively the detection efficiency and shortens the detection tome. In the case of mismatch, the method can pick out the state of island quickly and reliably through negative sequence voltage positive feedback makes an early warning signal.

\section{REFERENCES}

[1] X. Yaosuo, L.-C. Chang, Sren, B. Kjaer, J. Bordonau, and T. Shimizu, "Topologies of single-phase inverters for small distributed power generators: an overview," IEEE Transactions on Power Electronics, 2004, vol. 19, no. 5, pp. 1305-1314.

[2] L. Asiminoaei, R. Teodorescu, F. Blaabjerg et al., "A Digital Controlled PV-Inverter With Grid Impedance Estimation for ENS Detection," IEEE Trans. Power Electron, vol. 20, no. 6, pp: 1480-1490, 2005.

[3] Y. Gwon-jong, S. Jeong-Hoon, J. Young-Seok, C. Ju-yeop, J. Seung-Gi, K. Ki-Hyun, and L. Ki-ok, "Boundary conditions of reactive-power-variation method and active-frequency-drift method for islanding detection of grid-connected photovoltaic inverters," in Proc. Conference Record of the Thirty-first IEEE on Photovoltaic Specialists Conference, 2005, pp. 1785-1787.

[4] M. Karimi-Ghartemani and A Synchronization, Scheme Based on an Enhanced Phase-Locked Loop System, 2004.

[5] S. I. Jang and K. H. Kim, "An islanding detection method for distributed generations using voltage unbalance and total harmonic distortion of current," IEEE Tran. Power Delivery, vol. 19, no. 2, pp. 745-752, April 2004.

[6] J. Yin, L. Chang, and C. Diduch, "A new adaptive logic phase-shift algorithm for anti-islanding protections in inverter-based DG systems," in Proc. IEEE Power Electronics Specialists Conference, pp. 2482-2486, 2005.

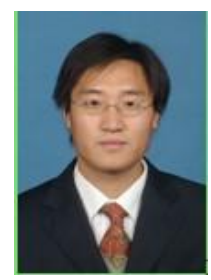

Zongjie Liu was born in Laiwu, Shandong Province in November, 1983. He has received the Bachelor's degree in Automation from Harbin Institute of Technology in June 2010. He works at Shandong Electric Power Group Corporation, Jining Power Supply Company. His location is Engineer.His current interest is automatic control in power system.

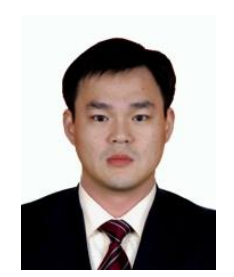

Lifeng Zhu was born in Qufu, Shandong Province, in October, 1975. He has received the Bachelor's degree in electrical engineering from North China Electric Power University in June 1998. He works at Shandong Electric Power Group Corporation, Jining Power Supply Company. His location is Senior Engineer. Previous publications: Rural Substation Voltage Regulation and Reactive. Power Compensation Package (Qufu,Shandong Province,Zhu Lifeng,2009). The Application of Distribution Automation in Distribution Production Management (Qufu,Shandong Province,Zhu Lifeng,2009). His current interests are smart gird and power system digital protection 